From: Cereal. Production. Proceedings of the Second International Summer School in Agriculture held by the Royal. Dublin Society. E.J. Gallagher (ed.). 1984

Chapter 26

\title{
Epidemiological and crop physiological foundation of EPIPRE
}

\section{R. Rabbinge}

Department of Theoretical Production Ecology, Agricultural University, Wageningen, The Netherlands

and

\section{F. H. Rijsdijk}

Department of Phytopathology, Agricultural University, Wageningen, The Netherlands

\section{Introduction}

EPIPRE (EPIdemics PREdiction and PREvention) is a system of supervised control of diseases and pests in winter wheat (Triticum aestivum) which operates in different cereal-growing areas of western Europe with a large number of different cultivars. In this system the participating farmers do their own disease and pest monitoring, according to well-defined simple and reliable observation and sampling techniques. This information is introduced into a computer, which produces recommendations for treatments designed to optimize returns from crop protection. Cereal aphids and five fungus diseases are incorporated in the system (Table 26.1).

In this chapter the epidemiological and crop physiological basis of EPIPRE is given, the general description of EPIPRE, its use and application having been given by Zadoks in Chapter 25 .

TABLE 26.1. EPIPRE: Supervised pest and disease management system for winter wheat in the Netherlands

\begin{tabular}{llll}
\hline Year & Disease & Causative organism & No. of fields \\
\hline 1978 & Yellow rust & Puccinia strifformis & 400 \\
1979 & Yellow rust & Puccinia striiformis & 450 \\
& Mildew & Erysiphe graminis & \\
1980 & English grain aphid & Sitobion avenae & 840 \\
& Yellow rust & Puccinia striiformis & \\
& Mildew & Erysiphe graminis & \\
& Brown rust & Puccinia recondita & \\
& English grain aphid & Sitobion avenae & \\
& Rose-grass aphid & Metopolophium dirhodum & \\
& Bird cherry-oat aphid & Rhopalosiphum padi & \\
& Yellow rust & Puccinia striiformis & \\
& Mildew & Erysiphe graminis & \\
& Brown rust & Puccinia recondita & \\
& Septoria spp. & Sitobion avenae & \\
& English grain aphid & Retopolophium dirhodum & Rhopalosiphum padi \\
& Bird cherry-oat aphid & &
\end{tabular}




\section{Predicted yield loss}

With the computed expected severity, after a prognosis period a loss expectation is calculated per pest and disease. Relations between severity and crop loss often show an S-shaped curve since, with low severities, no loss appears and, with high severities, the loss stabilizes. For decision making in most wheat diseases only the very beginning of the curve is important as a high severity will lead to disastrous crop losses. When the predicted severity would lead to a crop loss more than the maximum economic threshold (i.e. the loss equals the costs for treatment for only one pest or disease), a control measure is necessary. In case combined control measures are possible this may lower the economic threshold for each of the individual diseases. The calculated loss is expressed in a proportional loss of the expected yield. The expected final yield is based on the farmer's estimate of yield early in the season, and experience with wheat growing in the region. The relation between severity and percentage yield loss is affected by the developmental stage of the crop. In this way the changing susceptibility and effect of potential production of a crop on the effect of disease are introduced.

The calculations for cereal aphids are slightly different. In this case the peak density of the cereal aphids is computed and this is used to calculate the expected yield loss in $\mathrm{kg}$ wheat ha ${ }^{-1}$, from damage relations which depend on expected yield and growing conditions. This method is chosen as it appears that, due to changing crop conditions after stage 75 , and because of the effects of natural encmies and aphid pathogens, the cereal aphid populations reach a peak at crop development stage 77 or earlier (see p.232). Statistical analyses have shown that the relation between peak density and yield loss has the highest correlation coefficient $(r=$ 0.72 ). This relation assumes proportionality of yield loss with increasing cereal aphid density, which may be absent. Moreover it does not take into account the level and nature of yield loss at different crop yield levels. Nevertheless, this relation had to be used in the beginning of EPIPRE, as more accurate damage relations were not available. Later, other damage relations were introduced.

The effect of cereal aphids appears to be superproportional with yield: an aphid density of 15 aphids per tiller in the population peak gives a yield loss of $250 \mathrm{~kg}$ at a production level of $5000 \mathrm{~kg}$ wheat ha ${ }^{-1}$ whereas a similar density at a production level of $7500 \mathrm{~kg}$ wheat ha ${ }^{-1}$ may cause a yield loss of $1000 \mathrm{~kg}$ (Mantel, Rabbinge and en Sinke, 1982). Thus, control of cereal aphids is more important at high than at low production levels.

The reasons for this superproportional effect lie with the causes of yield deprivation. A detailed analysis (Rabbinge et al., 1981) has shown that direct assimilate consumption explains only a part of the total yield loss. At low yield levels $\left(\leqslant 5000 \mathrm{~kg} \mathrm{ha}^{-1}\right), 50 \%$ of the yield loss due to aphids is caused by assimilate consumption (Vereijken, 1979), whereas at high yield levels not more than $12 \%$ of the yield loss is due to assimilate consumption (Mantel et al., 1983). The other part of yield loss is caused by effects of the aphid's excretion product, viz. honeydew. Honeydew has a direct effect on the photosynthesis of the leaves by coverage of the stomates, it promotes leaf senescence as photochemically active enzymes are no longer stimulated, and honeydew has a positive effect on the population increase of saprophytic fungi ahd yeasts which may have a negative effect on the photosynthesis. Saprophytic fungi may also have a positive effect on yield because of the control of perthotrophic fungi, e.g. Septoria nodorum, through competition (Fokkema et al., 1979; Rabbinge et al., 1981), but this seems only important at low yield levels. 
analyses with the extensive population models, so-called summary models have been developed (Carter, Dixon and Rabbinge, 1982). These summary models use the average number of cereal aphids per tiller, determined as described above, as an input and compute the peak density of the cereal aphids in development stage DC 77. The computation applies the simple exponential growth formula described above, using a relative growth rate which depends only on crop development stage, and an estimate for the time period between the actual development stage and DC 77. When weather conditions deviate from the climatic conditions of that particular region, the input data for the decision programme, especially crop development stage, are actualized and new predictions are made.

Unfortunately, available knowledge on the potential of natural enemies to cereal aphids, including fungal pathogens (Entomophthora spp.), is so limited that they cannot yet be incorporated into the decision programme. The perspectives of natural enemies and fungal pathogens in biological control are, at this moment, low, but research being done in different places may lead to better methods and control agents, and thus will necessitate the introduction of these natural enemies in the decision programmes.

The epidemiological knowledge illustrated in detail above for cereal aphids is also available for stripe rust and brown rust. Similar methods have been used for these diseases to get decision programmes for their control. For mildew and leaf spot more detailed information is not available, therefore empirical methods and guestimates were used to get decision programmes. Detailed information on the nature and level of yield loss is not available for most diseases, therefore the superproportional relation between yield loss and yield level determined for cereal aphids is applied in the disease-plant relations. For mildew slightly different relations are used which are based on unpublished data of Daamen (personal communication). These relations show that an early effect of mildew may have a considerable effect on yield loss.

\section{Results of EPIPRE}

The EPIPRE system has been implemented and improved in the Netherlands since 1978. The number of participating fields started with 5ome 300 in 1978 and reached some 1100 in 1981 . About $6 \%$ of the Dutch winter wheat acreage is covered. As shown in Table 26.1 the number of pests and diseases incorporated in the system has increased considerably, a fairly complete package being offered nowadays.

The population dynamics of each of the diseases may differ and their crop loss relations may vary considerably. For each of the diseases appropriate summary models and computation rules are introduced.

During the years of experience with EPIPRE it has become clear that the confidence in the recommendations has grown. In $198038 \%$ of the participating fields were treated according to EPIPRE, in $198154 \%$ of the fields were treated according to EPIPRE. The reluctance of farmers to follow the EPIPRE recommendations completely may be explained by the significantly fewer treatments recommended, in comparison with other recommendation sources such as the Extension Service and the chemical industry. However, it is not to be expected that such a system ever will reach a $100 \%$ score, since there are often good reasons why a farmer does not obey the recommendations. The proof of the system is the participation of farmers, as they pay for their recommendations. 
A comparison of participating farmers' fields with EPIPRE recommendations, and other recommendation sources, shows that EPIPRE recommends significantly fewer treatments than other sources but that the net yield is similar or slightly higher (Table 26.4). The farmers with low yield levels are more inclined to follow EPIPRE recommendations than farmers with high yield levels. The disease and

TABLE 26.4. Comparison between net yields of fields treated according to EPIPRE and fields treated 'more than EPIPRE' in 1981

\begin{tabular}{llllllr}
\hline $\begin{array}{l}\text { Yield } \\
\text { class } \\
\left(t h a^{\prime}\right)\end{array}$ & $\begin{array}{l}\text { Net yield } \\
\text { EPIPRE } \\
\left(t h a^{-1}\right)\end{array}$ & $\begin{array}{l}\text { Net yield } \\
\text { 'more than } \\
\text { EPIPRE' } \\
\left(t \text { ha }^{-1}\right)\end{array}$ & $\begin{array}{l}\text { Costs of } \\
\text { treatment } \\
\text { EPIPRE } \\
(t \text { hat }\end{array}$ & $\begin{array}{l}\text { Costs of } \\
\text { treatment } \\
\text { 'more than } \\
\text { EPIPRE' } \\
\left(t h a^{-1}\right)\end{array}$ & $\begin{array}{l}\text { \% fields } \\
\text { treated } \\
\text { according to } \\
\text { EPIPRE }\end{array}$ & $\begin{array}{l}\text { No. of } \\
\text { fields }\end{array}$ \\
\hline 6 & 5.34 & 4.93 & 0.15 & 0.45 & 75 & 69 \\
$6-8$ & 6.90 & 6.77 & 0.23 & 0.41 & 57 & 524 \\
8 & 8.16 & 8.13 & 0.31 & 0.45 & 41 & 263 \\
\hline
\end{tabular}

pest situation has been quite different in the different years. In 1978, 1979 and 1980 there were virtually no important diseases; only cereal aphids, especially Metopolophium dirhodum, were important in 1979. In 1981 a large number of fields suffered from mildew and cereal aphids, mainly Sitobion avenae, but also Septoria spp. were important. Mildew was important early in the season and Septoria and cereal aphids after flowering.

\section{Summary}

Although EPIPRE has only a short history it appears very clearly that there exists a demand for a supervised pest and disease management system for winter wheat.

This system or infrastructure enables the scientist to channel his information concerning population dynamics of pests and diseases and crop loss directly to the farmer's field. Changes in cultivars, agricultural methods, susceptibility and virulence may be introduced immediately in the system and may alter recommendations. The advantages of EPIPRE for the farmers are the direct ties with research and the reminders to monitor their wheat crop in a particular way. For the research workers it has the advantage that new problems arising in the field are immediately formulated and incorporated.

For agriculture as a whole this supervised system has the advantage of a decreased use of pesticides and a decrease in the risk for development of resistance of fungi and insects against pesticides. In the future the system may be extended into a complete crop management system in which nitrogen fertilization, weed control and other agronomical measures are incorporated.

The system is now run centrally on a big computer, storing data from many fields. In the near future EPIPRE may be available as a soft-ware package for microcomputers which can be used by the farmers, individually or in groups, on their own equipment. 
The role of meteorological data in the EPIPRE system is limited, as the repetitive observations and the introduction of physiological time (crop development stage) appears to be sufficiently accurate. Whenever detailed weather data are needed for other diseases this may be incorporated in the central system as the central computer is connected to the computer of the Royal Netherlands Meteorological Institute. In case microcomputers are used meteorological data measuring equipment should be used which is adapted to the size of these systems.

In this way these management systems may help to reach the final aim of an agriculture in which energy and pesticide use is optimized instead of maximized.

\section{References}

ANkersmit, G. W. and CARTER, N. (1981). Comparison of the epidemiology of Metopolophium dirhodum and Sitobion avenae on winter wheat. Neth. J. Pl. Path., 87, 71-81

CAR'TER, N., DIXON, A. F. G. and RABBINGE, R. (1982). Cereal aphid populations: biology, simulation and prediction. Simulation Monographs, Wageningen, Netherlands, Pudoc, $91 \mathrm{pp}$.

FOKKEMA, N. J., HOUTER, J. G. DEN, KOSTERMAN, Y. J. C. and NELIS, A. L. (1979). Manipulation of yeasts on field-grown wheat leaves and their antagonistic effect on Cochliobolus sativus and Septoria nodorum. Trans. Br. mycol. Soc., 72, 19-29

MANTEL, W. P., RABBINGE, R. and WINKE, J. (1982). Effecten van bladluizen op de opbrengst van wintertarwe. Gewasbescherming, 13, 115-124

RABBINGE, R. and MANTEL, w. P. (1981). Monitoring for cereal aphids in winter wheat. Neth. J. Pl. Path., $87,25-29$

RABBINGE, R., ANKERSMIT, G. W. and PAK, G. A. (1979). Epidemiology and simulation of population development of Sitobion avenae in winter wheat. Neth. J. Pl. Path., 85, 197-220

RABBINGE, R., DREES, E. M., GRAAF, M. VAN DER, VERBERNE, F. C. M. and WESSELO, A. (1981). Damage effects of cereal aphids in wheat. Neth. J. Pl. Path., 87, 217-233

VEREIJKEN, P. H. (1979). Feeding and multiplication of three cereal aphid species and their effect on yield of winter wheat. Agric. Res. Rep., No. 888, Pudoc, Wageningen

ZADOKS, J. C. CHANG, T. T. and KONZAK, C. F. (1974). A decimal code for the growth stages of cereals. Weed Res., 14, 415-421 